

Editorial

\title{
Understanding the nature of congenital division of the atrial chambers
}

Although the atriums must bow to the ventricles in terms of the power and complexity of the contractions of their muscular walls, morphologically they are far more complex than the mere forechambers implied by their classical name (defined in the Shorter Oxford Dictionary as "a portico in front of the principal doors of churches, etc". ${ }^{1}$ The atriums are particularly important to those practitioners dealing with cardiology in the young, since recognition of their arrangement is the first step in the process of diagnosis now known generally as sequential segmental analysis. ${ }^{23}$ In addition to recognising the disposition of the atriums relative to each other, however, the paediatric cardiologist must also recognise atrial malformations, no matter how rare or arcane they may be. It is a truism that recognition of such lesions is greatly enhanced when their morphology is understood.

This sets the scene for the discussion of hearts characterised by some degree of congenital partitioning within the morphologically left atrium. The reports collected in this issue of the British Heart Journal describe the use of colour flow mapping in diagnosis of division of the left atrium in association with congenitally corrected transposition; ${ }^{4}$ diagnosis of a more classic case of divided left atrium by transoesophageal echocardiography; ${ }^{5}$ and, perhaps most interestingly, a description of two cases with a prominent shelf guarding the entrance of the left pulmonary vein to the left atrium. ${ }^{6}$ Although all the authors point to the rarity of such malformations, the April issue of Pediatric Cardiology too carries a report of a rare variant of divided left atrium, ${ }^{7}$ as well as an account of the experience of Columbia University, New York, over a 28 year period, which encompassed 12 cases. ${ }^{8}$ The importance of these lesions to all cardiologists is emphasised by the fact that both the patients from Boston ${ }^{6}$ were adults referred for evaluation of a left atrial mass detected echocardiographically, while the patient studied at the Royal London Hospital was also an adult presenting with mitral stenosis in the third decade of life. ${ }^{5}$ No longer, therefore, can adult cardiologists claim that such cases do not influence their practice. They may be rare but, as shown in these reports, they are readily recognised by cross sectional echocardiography and, providing their anatomy is understood they are easy to categorise and describe.

\section{Unnecessary difficulties in description}

A review of the cases presented on pages 4,6 , and 9 of this issue along with those in Pediatric Cardiology,${ }^{78}$ shows that the popular term for description (and that almost universally adopted by the specialists) is "cor triatriatum sinister". The alternative offered by the Boston group is "remnant of the common pulmonary vein." In their discussion, however, Manning and his colleagues ${ }^{6}$ steer towards the more conventional "cor triatriatum", albeit giving an incorrect account of the developmental theory offered for the lesion by their cited embryologists. ${ }^{9}$ More of the embryology later, but what of the description? What is "cor triatriatum sinister"? Anyone with the merest smattering of classical education (which is the most to which many of us can now lay claim) would interpret this to mean a heart with three left atriums! Is that what the term is meant to describe? Of course not. All the cases described show some degree of division of the left atrium. And it is known that the right atrium can similarly be congenitally divided. In my former years, I, too, was foolish enough to describe such a case as "cor triatriatum dexter". ${ }^{10}$ But that was also when I wrote incomprehensible embryological dissertation s $^{11}$ which, in retrospect, did little to enhance the understanding of congenital malformations.

I now believe we should describe these cases with simple English words, and, until we have strong evidence of the correct mechanics of cardiac development, we should eschew speculative embryology. Then if we look at previous accounts we see that "cor triatriatum sinister" is usually accompanied by a parenthetical English translation (subdivided left atrium.) ${ }^{1213}$ It is on the basis of division of the morphologically left atrium that the lesion is simply understood and, more importantly, correctly described.

\section{Structure of the atriums}

The atrial chambers have a comparable structure on the right and left sides of the normal heart, albeit with differences sufficiently distinct to permit their ready differentiation. On both sides the atriums possess a venous component, an appendage, and a vestibule. There is also a septum separating the atriums with characteristic features on its morphologically left and right sides. But the atrial septum can be totally lacking in morphologically abnormal hearts, producing a common atrium. The venous components of the atriums can also be totally deficient. It is the structure of the appendage, therefore, particularly the anatomy of its junction with the venous component of the atrium (fig $1 \mathrm{C}$ ), that most readily permits the distinction of morphologically right and left atrial chambers. ${ }^{14}$ It is usual during development of the morphologically right atrium for sheet-like valves to direct the richly oxygenated venous return from the inferior caval vein across the oval foramen to the left side of the heart and thence towards the developing brain. These valvar structures can remain unduly prominent in postnatal life, ${ }^{15}$ and are then the anatomical substrate for division of the morphologically right atrium. ${ }^{10}$

Division of the morphologically left atrium takes a 


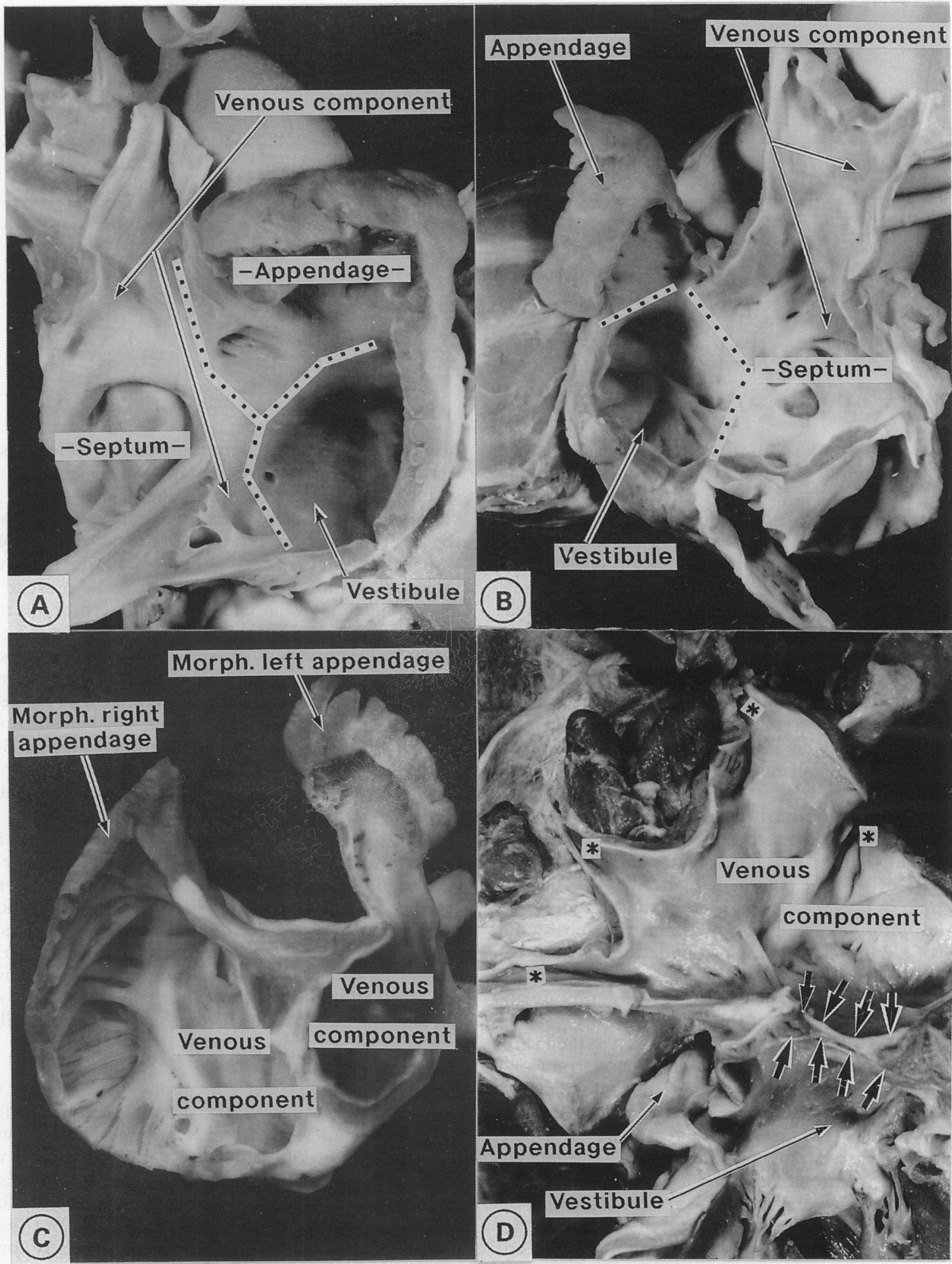

These illustrations of normal human hearts show the features of $(A)$ the morphologically (morph.) right and $(B)$ the morphologically left atriums together with (C) the characteristic morphological differences between the two appendages based on the nature of their junctions with the venous components of the atriums. The heart shown in $D$ is an example of the classic form of divided left atrium, with a prominent fibromuscular partition (between arrows) separating the pulmonary venous component from the rest of the left atrium. The asterisks show the four pulmonary veins. The lines on $A$ and $B$ are for the purposes of illustrating a concept-they do not demarcate obvious gross anatomical boundaries.

markedly different form. In this lesion, a fibromuscular partition is found between the venous component of the atrium and the remaining atrial components (fig 1D). This partition has no counterpart during normal development. It usually extends obliquely across the cavity of the atrium, and is most frequently positioned so that the oval fossa opens into the non-venous atrial component. The severity and timing of presentation is related to the size of the opening between the divided atrial components. The variety in position of the shelf, however, is legion. While association with other lesions permits truly mind-bending classifications to be assembled for the overall expression of the lesion. ${ }^{13} \mathrm{My}$ own preference is to describe simply the existence of the divided atrium and then list the associated 
lesions, particularly important confounding ones such as totally anomalous pulmonary venous connexion. ${ }^{7}$

\section{Development of the lesion}

Two of the reports in this issue offer embryological explanations of the lesions observed, ${ }^{56}$ although the third, perhaps wisely, refrains from such speculations. ${ }^{4}$ Conventional wisdom holds that the common pulmonary vein grows out from the developing atrium to make contact with the intrapulmonary venous plexus developing within the lung buds, and that subsequent incorporation of this venous plexus into the left atrium produces the typical arrangement of the left atrium with a pulmonary vein at each corner. Division of the left atrium is then explained either on the basis of malincorporation of the common pulmonary vein, or alternatively, as proposed by Van Praagh and Corsini, ${ }^{9}$ its entrapment by the developing left sinus horn. As HL Mencken commented "there's always an easy solution to every human problem-neat, plausible and wrong". ${ }^{16}$ The embryological hypotheses are based upon the study of serially sectioned human embryos-itself a very inexact science. Studies of graded animal models with immunocytological markers that distinguish the different developmental components will soon permit us to offer more exact accounts of atrial development. In the meantime, it seems imprudent to base concepts of abnormal hearts on such questionable premises. As the group from Riyadh point out ${ }^{7}$ it is difficult to explain the coexistence of divided left atrium and totally anomalous pulmonary venous drainage on the basis of either theory.

\section{Congenital heart disease made easy}

In this issue of the British Heart Journal readers are confronted by four examples of rare congenitally malformed hearts. Two show the classic form of division of the left atrium. The other two show a previously undescribed (to my knowledge) variant in which a partition extends into the cavity of the left atrium between the openings of the left upper pulmonary vein and the left atrial appendage. This latter account is perhaps the most interesting. It is entirely reasonable to propose that this lesion is a minimal expression of the shelf that typically partitions the chamber in classically divided left atrium. The rapid advances presently being made in the study of cardiac development soon may permit us to make more accurate guesses at the nature of the dividing partition. In the meantime, it makes most sense to me to describe the cases in terms of division of the morphologically left atrium and to recognise that the fibromuscular shelf separates the pulmonary venous component from the remainder of the atrium.

ROBERT H ANDERSON

Department of Paediatrics,

National Heart and Lung Institute,

Royal Brompton National Heart and Lung Hospitals,

Dovehouse Street, London SW3 $6 L Y$

1 Little W, Fowler HW, Coulson J. In: Onions CT ed. The shorter Oxford English dictionary on historical principles. 3rd ed (GWS Friedrichsen) English dictionary on historical princi
Oxford: Clarendon Press, 1973:126.

2 Tynan MJ, Becker AE, Macartney FJ, Quero-Jimenez M, Shinebourne EA Anderson RH. Nomenclature and classification of congenital heart disease. Anderson RH. Nomenclature

3 Anderson RH, Becker AE, Freedom RM, Macartney FJ, Quero-Jimenez M Shinebourne EA, Wilkinson JL, Tynan MJ. Sequential segmenta analysis of congenital heart disease. Pediatr Cardiol 1984;5:281-8.

4 Alwi M, Hamid ZAA, Zambahari R. A characteristic continuous wave Doppler signal in cor triatriatum? Br Heart J 1992;68:6-8.

5 de Belder MA, Argano V, Burrell CJ. Cor triatriatum sinister, not mitra stenosis, in an adult with previous Sydenham's chorea: diagnosis and preoperative assessment by cross sectional echocardiography. Br Heart 1992;68:9-11.

6 Manning WJ, Waksmonski CA, Riley MF. Remnant of the common pulmonary vein mistaken for a left atrial mass: clarification by transpuesophageal echocardiograpy. Br Heart J 1992:68:4-5.

7 Al-Fodey F, echocardiography. Br Heart J $1992 ; 68$ : total anomalous pulmonary venous drainage in the setting of mitral atresia and a restrictive interatrial communication. Pediatr Cardiol 1992;13: and a 6 .

8 Gheissari A, Malm JR, Bowman FO Jr, Bierman FZ. Cor triatriatum sinister: one institution's 28-year experience. Pediatr Cardiol 1992;13: 85-8.

9 Van Praagh R, Corsini I. Cor triatriatum: pathologic anatomy and a consideration of morphogenesis based on 13 postmortem cases and a study of normal development of the pulmonary vein and atrial septum in 8 human embryos. Am Heart J 1969;78:379-405.

10 Gerlis IM, Anderson RH. Cor triatriatum dexter with imperforate Ebstein's anomaly. Br Heart $J$ 1976;38:108-11.

11 Anderson RH, Wilkinson JL, Arnold R, Lubkiewicz K. Morphogenesis of bulboventricular malformations. 1: Consideration of embryogenesis in the normal heart. Br Heart $J$ 1974;36:242-55.

12 Richardson JV, Doty DB, Siewers RD, Zuberbuhler JR. Cor triatriatum (subdivided left atrium). J Thorac Cardiovasc Surg 1981;81:232-8.

13 Thilenius OG, Bharati S, Lev M. Subdivided left atrium: an expanded concept of cor triatriatrum sinistrum. Am J Cardiol 1976;37:743-52.

14 Sharma S, Devine W, Anderson RH, Zuberbuhler JR. The determination of atrial arrangement by examination of appendage morphology in 1842 atrial arrangement by examination of appendage

15 Trento A, Zuberbuhler JR, Anderson RH, Park SC, Siewers RD. Divided right atrium (prominence of the Eustachian and Thebesian valves) right atrium (prominence of the Eustac
$J$ Thorac Cardiovasc Surg 1988;96:457-63.

16 Mencken HL. In: Peter L, ed. Quotations for our time. London: Magnum. $1980 ; 480$. 